\title{
Environmental Sustainability Evaluation of Apparel Product: A Case Study on Knitted T-Shirt
}

\author{
Md. Mazedul Islam ${ }^{1}$ and Md. Mashiur Rahman Khan ${ }^{2}$ \\ ${ }^{1}$ Department of Textile Engineering, Dhaka University of Engineering \& Technology, Gazipur 1700, Bangladesh \\ ${ }^{2}$ Department of Apparel Manufacturing Engineering, Bangladesh University of Textiles, Tejgaon, Dhaka 1208, Bangladesh
}

Correspondence should be addressed to Md. Mazedul Islam; mazed.butex77@gmail.com

and Md. Mashiur Rahman Khan; mrktex@yahoo.com

Received 15 September 2014; Accepted 5 November 2014; Published 24 November 2014

Academic Editor: Anindya Ghosh

Copyright (C) 2014 Md. M. Islam and Md. M. R. Khan. This is an open access article distributed under the Creative Commons Attribution License, which permits unrestricted use, distribution, and reproduction in any medium, provided the original work is properly cited.

\begin{abstract}
The work reported in this paper presents the assessment of environmental performances of selected branded apparel T-Shirt products made by Bangladesh. The study is based on a standard evaluation tool named Higg Index which is basically used widely to measure the environmental sustainability of various apparel products. Higg Index is an internal self-assessment tool created by the outdoor apparel industry and Nike's apparel environmental design tool which aims to aggregate information on the environmental performance of products. The Index considers performance across the full life-cycle of a product, including impacts from "input materials, manufacturing, packaging, transportation, use, and end-of-life." Selected apparel branded T-Shirt products from S. Oliver, BUTex-Innovation, PUMA, Esprit, Aarong, and Yellow were taken into consideration. The results indicate that newly developed ecofriendly T-shirt and foreign branded products named S. Oliver, PUMA, and Esprit gained higher score but local branded product like Aarong and Yellow gained lower score in terms of environmental sustainability based on Higg Index assessment tool. Moreover, many weaknesses and opportunities for improvement of both local and foreign branded T-Shirt products have been identified and suggested which would eventually lead the fashion designer, apparel manufacturer, stakeholder, and consumer towards greener apparel products.
\end{abstract}

\section{Introduction}

Sustainability is the major concern in the age of modern world. For textile and apparel sector, this has been a burning issue for many related concerned bodies. Over the past few years, increasing awareness of the environmental and social concerns surrounding the fashion industry have led to a rise in the implementation of sustainability initiatives. There has been a growing concern over apparel brands in improving their environmental impact and the social responsibility throughout their supply chains. Environmental sustainability refers to the ability of something to continue without upsetting earth's ecological balance. Sustainable apparel products can be defined as a part of the growing design philosophy and trend of sustainability, the goal of which is to create a system which can be supported indefinitely in terms of environmentalism and social responsibility [1]. Environmental sustainability in business refers to longevity, but in terms of which natural resources the production process might draw upon, how resources are used and replenished, the overall impact of the final production on the environment, and where the product ends up following its disposal. The textile and apparel products impact the environment at every point along the product's lifecycle [1]. However, rapid growth in the industrial sector is playing a vital role in the economy of Bangladesh. Despite the growing necessity of environmental practices in the apparel industry, little research has explored methods and standard tools to guide apparel designers, manufacturers, merchandisers, and consumers in adapting environmental issues in their work. Many designers do not recognize how their designs impact the environment. The role of the designer must expand dramatically in light of current environmental concerns with the contamination and destruction of the ecosystem [2]. Today's designer, manufacturer, merchandiser, and consumer must be well informed on a vast array of topics, from methods of production to 
governmental regulations to life cycle analysis. They must account for the environmental impacts of the materials uses, the resulting waste from the forms they chooses, how products are produced and packaged, where they will be made and then sold causing energy use for transportation, and how consumers may use and dispose of the product [3]. Hence, there is a growing need to measure the environmental sustainability of apparel products by standard methods, tools, and technique to minimize the environmental impact. The Higg Index by sustainable apparel coalition is such a standard tool by which the environmental sustainability of apparel products could be measured. This study attempts to identify and analyse a number of these issues related to apparel product sustainability taking several local and foreign branded T-shirts into consideration as case study.

\section{Literature Review}

2.1. Sustainable Apparel Product. Sustainability is defined as the design of human and industrial systems to ensure that humankind's use of natural resources and cycles do not lead to diminished quality of life due either to losses in future economic opportunities or to adverse impacts on social conditions, human health, and the environment [3]. To achieve sustainable development, designers need to be aware of environmental impacts and incorporate environmental awareness into the design [2]. Product sustainability is the easiest aspect to alter for an apparel brand, as this is where a company has the most and direct control through design and product development [2]. Transforming product sustainability may be achieved via various aspects such as fiber/textile selection, processing methods, use behaviors, and reuse/recycle strategies. Fiber/textile selection is often the first step that designers and product developers will take in reducing the environmental impact of a garment. Environmentally preferred fibres/textiles can significantly reduce the environmental impact and increase the resourcefulness of an apparel product throughout the garments life cycle without change to design practice or product development processes [3].

\subsection{Environmental Impact of Textiles Apparel Products. The} apparel industry has many negative environmental and social impacts that are complex and occur at different stages of the apparel life cycle. The development of fast fashion has amplified the impacts due to the increased volume of apparel produced and sold at low prices [4]. Apparel has a long and complicated production chain consisting of many phases including resource production and extraction, fibre and yarn manufacturing, textile manufacturing, apparel assembly, packaging, transportation and distribution, consumer use, recycling, and ultimate disposal [5]. The environmental impacts of apparel are varied across the phases, difficult to assess for individual garments, and subject to type of raw material used, dyeing, and laundering. It was not until the 1990s that there was a greater awareness as to the severity of the negative environmental impacts of apparel production [3]. The major environmental impacts associated with the production and use of apparel throughout its life cycle includes wastewater emissions from dyeing, finishing, and washing processes, increase in pollution, solid waste production, and significant depletion of resources from consumption of water, fossil fuels, and raw materials [2, 6]. Energy is used for laundering, transportation, operations of machines for various processes, production of primary materials especially man-made fibres such as polyester (a petroleum based product) and yarn manufacturing of natural fibres such as cotton. Conventional cotton production has high water consumption and employs the use of toxic chemicals that may harm human health and the environment $[1,7]$. Chemicals are also released in wastewater from processes such as pretreatments, dyeing, finishing, and laundry. These chemicals are disruptive to both the environment and aquatic-based life [8]. Solid waste is produced during natural fibre yarn, textile, and apparel manufacturing and disposal of apparel products at the end of their life. There are significant issues with clothing waste as the majority of clothing and textile waste ends up in landfills as opposed to being recycled or reused [2].

2.3. Sustainable Apparel Coalition and Higg Index Tool. The SAC is a multistakeholder engagement, formed in 2011, by a group of global apparel and footwear companies and nonprofit organizations representing nearly one third of the global market share for apparel and footwear. The SAC seeks to build a common approach for measuring and evaluating apparel and footwear product sustainability performance [9]. It aims to develop common measurements and a common environmental understanding of products' impacts across the industry by building on the Outdoor Industry Association (OIA)'s Eco Index and Nike's Environmental Design tool [10]. The Eco Index is a standardized tool for measuring the environmental impacts of outdoor products such as boots, clothing, and tents and evaluates the impacts in six key areas of a product's life cycle: materials, packaging, product manufacturing, and assembly, transport and distribution, use of service, and end of life [9]. Nike's Environmental Design tool measures the environmental impacts of apparel. Measuring performance of apparel products will spotlight priorities for action and opportunities for technological innovation [9]. The Higg index 1.0 is an "indicator based tool for apparel that enables companies to evaluate material types, products, facilities, and processes based on a range of environmental and product design choices" [9]. The scope for the desired outcomes of the SAC Higg Index 1.0 tool includes improvements to reduce water use and improve quality, reduce energy and emissions, minimizing waste, reduce chemicals and toxicity, and increase transparency for social and labour issues [6]. The first version of the Higg Index 1.0 tool which was released in June 2012 was based on life cycle thinking and is publicly available for any organization. The Index tool was developed to measure the environmental impacts of apparel products. The tool evaluates material type, products, and facilities and processes. By utilizing practice based, qualitative binary yes/no questions, assessments can be made as to the sustainability performance of product and drive behavior for improvement. The Higg Index RDMBeta is a prototype aims at educating and providing quick 
directional guidance to apparel designers during the product creation process about the potential environmental impacts of their design solutions [11]. It is to engage designers in the Higg Index's produce life cycle thinking and how we directionally assess materials sustainability through the MSI. By helping organizations standardize measurement and evaluation of environmental performance, the tool creates a starting point for engagement, education, and collaboration among stakeholders [12]. Through self-assessment, organizations can better understand the environmental impacts that occur throughout the life cycle and the effect of design choices such as material type. However, there are many apparel brands belonging to the SAC such as H\&M, Gap Inc., Nike, adidas, Puma, Patagonia, Mountain Equipment Co-op (MEC), Levi's, Hanesbrand, Marks \& Spencer, Esprit, Columbia, Timberland and Loomstate, and S. Oliver. These brands are widely using this Higg Index tool to measure environmental performance of their apparel products towards better sustainability [11].

\section{Materials and Methodology}

To carry out this study, selected knitted men's T-shirt products of $100 \%$ cotton single jersey fabric were taken into consideration as case study. Both foreign and local branded knitted men's "M" sized short sleeve T-shirt products, namely, S. Oliver, BUTex Innovation, PUMA, Levi's, Aarong, and Yellow, were selected on random basis to measure their environmental performance. The PUMA, S. Oliver, and Esprit branded T-shirts were collected from various organizations, namely, Viyellatex group Ltd. And Yellow and Aarong T-shirts were collected from Beximco fashion wear and Aarong and BUTex Innovation T-shirts were developed by the researcher as ecofriendly. Higg Index provides a value that represents how environmentally responsible an apparel item is in terms of sustainability. For this study, the tool was used to obtain product scores for the above mentioned TShirt. This score was obtained by answering questions relating to the materials, packaging, manufacturing, product care, and repair service, and product end of life. The data used during this process includes information readily available to the general consumers, manufacturers and merchandisers including hangtags, care labels, and online product descriptions and throughout the LCA phase of the developed T-Shirt. The product Tec-pack details information was the important sources for various Higg Index required information towards sustainability measurement. Higg Index 1.0 requires that all materials present be entered into a materials input table. This includes a description of all materials used in addition to information obtained from follow-up questions. By utilizing practice based, qualitative binary yes/no questions, assessments can be made as to the sustainability performance of product and drive behavior for improvement. Higg Index 1.0 is a Microsoft Office Excel and wed based tool that has predetermined standard values based on global survey for specific materials that are used in determining a score. The higher the Higg Index score, the better the environmental performance of an apparel products.

\section{Results and Discussions}

In this study, all the five selected foreign and local branded knitted T-shirts alone with new developed one were assessed using the Higg Index 1.0 to obtain a value that represents a product's environmental impact. A higher score implies a more sustainable product. Upon completion of the excel and web based Higg Index tool, the BUTex-Innovation, S. Oliver, PUMA, Esprit, Yellow, and Aarong T-shirts received total score of $75,57,79,53,47$, and 36 , respectively, on a scale of 1-100. The superior score of the BUTex Innovation and foreign banded product especially PUMA T-shirt was due to the organic material content, ecofriendly raw materials and process used product end of life options and confirmed traceability. On the other hand the local branded T-shirt gained comparatively lower score in most of the areas due not using ecofriendly raw materials, manufacturing processes, high impact finishes, improper or insufficient care and repair instructions, traceability issues, and so forth. This also confirms that by increasing the transparency of a product and offering more information about a product's development, the more this product will represent ecofriendliness and will be superior in terms of sustainability.

4.1. Materials Selection. The materials selected for the knitted T-shirt for both foreign and local branded product were entered into the material inputs table in the Higg Index 1.0. tool. The values obtained by various products are shown in Table 1. The developed men's T-shirt and foreign brands PUMA, S. Oliver, and Esprit obtained higher score. This was due to the ecofriendly raw materials used, that is, BUTex Innovation and PUMA t-shirt included 100\% organic cotton fibre. During processing of fabric, BUTex Innovation T-Shirt, PUMA, and other foreign branded T-shirts used ecofriendly and certified and environmentally low impacted dyes chemicals. But in case of local branded Yellow and Aarong T-shirts Higg Index score was lower due to environmentally hazardous conventional raw materials, processing, dyes used, no third party verification, and so forth. For better environmental sustainability these issues must be addressed for local branded apparel products.

4.2. Manufacturing Stages. The manufacturing stages are obviously an important area for better product sustainability. Some major issues have great impact on product environmental sustainability as per Higg Index tool. The developed men's T-shirt, PUMA, and foreign branded T-shirt used low impact garment finish, that is, process combination enzyme wash or basic rinse that scored higher. But local branded Aarong and Yellow T-shirt used high impact garment finish, namely, traditional bleach, acid chemical wash, and so forth and scored lower. Besides, marker efficiency has great impact on product sustainability. The higher the marker efficiency, the better the product sustainability and lower marker efficiency indicate its direct impact on supply chain including more wastages of material like fabric, dyes chemicals, process loss, land fill, and so forth. As developed T-shirt, PUMA, S. Oliver, and Esprit brand had more than $92 \%$ marker 


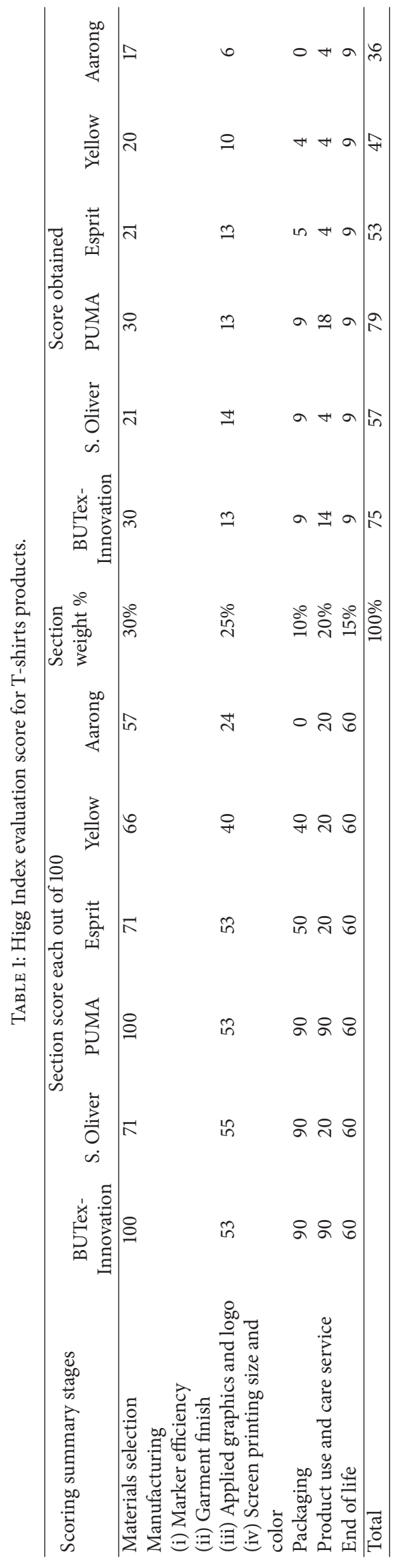




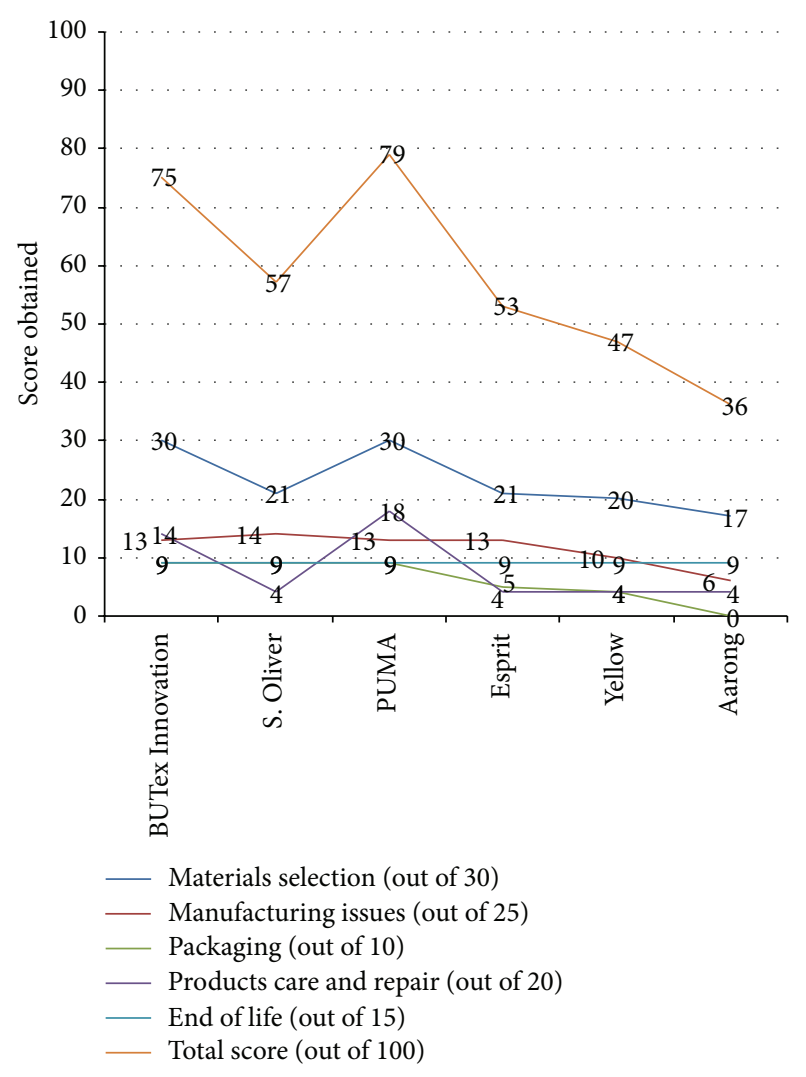

FIgURE 1: Higg Index assessment score for various branded T-Shirt.

efficiency, they scored better. But Aarong and Yelllow brands had marker efficiency of $78 \%$ and $84 \%$ and scored lower in the Higg Index tool. Similarly, a single colored, screen printed logo with small area received a higher score of for foreign branded T-shirt and these issues scored lower for local branded T-shirt. The total points for manufacturing stages are shown in Figure 1.

4.3. Packaging. Product packaging was included in this assessment. Conventional and environmentally harmful materials were used for local branded T-shirt especially in case of Aarong, which did not provide any score points rather than zero. But PUMA and other T-shirt used only sustainable, third party verified and reduced packaging materials and obtained better score. The packaging scores are shown in Table 1.

4.4. Product Care and Repair Services. For PUMA, new developed men's T-Shirt, S. Oliver, and Esprit T-shirts, best class to low impact details care instructions were provided due to the required care of the chosen materials that scored higher, that is, 18 for PUMA. But for Yellow and Aarong Tshirts, there were no in details care instructions that leaded to lower score in Higg Index, that is, only 4. Proper care instructions should be provided to the product label as most of the water and energy is used by the customer during the care and repair service stages.
4.5. End of Life. All T-shirt products received 60 points and a base score 9 for product end of life. The PUMA and BUTex Innovation product is made from $100 \%$ organic cotton and other branded T-shirt made from conventional cotton. These individual material types can be accurately identified by end of use facilities or processes. The material types are recycled via existing infrastructure and processes or materials are used in closed-loop recycling processes were not known. In response to the questionnaires regarding end of life of products as per assessment Higg Index tools, the all products responded in the same way to the questionnaires. So the EOL stages obtained a base score, that is, $60 \%$, and no additional points were given as shown in Table 1.

\section{Technical Issues for Apparel Products Sustainability Improvement}

The researcher has identified many technical requirements issues for apparel products sustainability improvement based on Higg Index assessment tool.

Sourcing Fair Production and Practice Transparency. Sourcing fair production can be performed by selecting manufacturers that are known to operate in a socially responsible manner. For the technical requirement of practicing transparency, the researcher suggests a hangtag including maximum in details information to the products that includes the name and contact information of a hypothetical manufacturer. This would allow a customer to verify socially responsible methods were practiced when the product was produced.

Sourcing Local Production. Local production is a valuable asset to improve product sustainability. This will also improve the social and economic sustainability of a product.

Consider Waste Reducing Design and Clean Production Adjustments. To reduce waste, the researcher suggested using ecofriendly dyeing method like reduced water dyeing or waterless dyeing method for the fabric processing. An onproduct label with instructions to recycle, reuse of the product, thus reducing waste, should be added to the label. Clean production can be achieved by selecting manufacturers that make a commitment to the use of alternative or renewable energies.

Consider Organic and Natural Fibers. Natural fibers are often viewed as the most environmentally responsible as they come from renewable sources and use less energy and chemicals to produce than manufactured fibers. Ecofriendly fibers, production methods that demand fewer natural resources and use nature to their benefit should be used.

Source of CMT Production. In order to replicate the possible effects of sourcing CMT production, the researcher decided to identify only one manufacturing facility instead of two or more in the Higg Index 1.0 to determine if fewer facilities results in a better score. 
Consider Natural and Low Impact Dyes and Chemicals. The designers, manufacturers, and merchandiser should introduce natural and environmentally low impact dyes in materials processing to better product sustainability.

\section{Conclusion}

The textile and apparel industries are notorious for their excessive contribution of waste and pollution to our environment. The unsustainable practices trends of poorly designing, raw materials selection, processing, manufacturing, and disposing of apparel product is a major contributing factor to this problem. The purpose of this study was to evaluate the environmental sustainability of various branded T-shirts and find out various sustainable issues for greener apparel products. Based on Higg Index environmental assessment standard tool, the findings of this study could be helpful for many organizations and customers who attempt to produce and consume sustainable textiles and clothing products. Both the local and foreign branded products should be produced by strictly maintaining sustainability issues. Hence, this study is a little approach towards better sustainable practices and eventually would drive the textile and clothing designer, manufacturers, merchandisers, and consumers to introduce various sustainable issues in their works. Hence, growing awareness and leading them towards sustainable practices in the textile and clothing business for greener world.

\section{Conflict of Interests}

The authors declare that there is no conflict of interests regarding the publication of this paper.

\section{References}

[1] J. M. Allwood, S. E. Laursen, C. M. de Rodriguez, and N. M. P. Bocken, Well Dressed? The Present and Future Sustainability of Clothing and Textiles in the United Kingdom, Institute of Manufacturing, University of Cambridge, Cambridge, UK, 2006.

[2] K. Fletcher, Sustainable Fashion \& Textiles, Earthscan, London, UK, 2008.

[3] C. A. Rusinko, "Green manufacturing: An evaluation of environmentally sustainable manufacturing practices and their impact on competitive outcomes," IEEE Transactions on Engineering Management, vol. 54, no. 3, pp. 445-454, 2007.

[4] J. K. Steinberger, D. Friot, O. Jolliet, and S. Erkman, "A spatially explicit life cycle inventory of the global textile chain," The International Journal of Life Cycle Assessment, vol. 14, no. 5, pp. 443-455, 2009.

[5] V. D. Lewis and C. Chen, "The life of a piece of cloth: developing garments into a sustainable service system," International Journal of Environmental, Cultural, Economic and Social Sustainability, vol. 2, no. 1, pp. 197-207, 2006.

[6] H. Goworek, "Social and environmental sustainability in the clothing industry: a case study of a fair trade retailer," Social Responsibility Journal, vol. 7, no. 1, pp. 74-86, 2011.

[7] J. Speer, "Organic cotton: where, why and how. Appare," Journal of Sustainable Textiles Materials, vol. 46, no. 9, pp. 29-34, 2005.
[8] S. E. Laursen, J. Hansen, H. H. Knudsen, H. Wenzel, H. F. Larsen, and F. M. Kristensen, EDIPTEX: Environmental Assessment of Textiles, Danish Environmental Protection Agency, Copenhagen, Denmark, 2007.

[9] The higg index, "Sustainable Apparel Coalition," 2012, http:// www.apparelcoalition.org/higgindex.

[10] K. Niinimäki and L. Hassi, "Emerging design strategies in sustainable production and consumption of textiles and clothing," Journal of Cleaner Production, vol. 19, no. 16, pp. 1876-1883, 2011.

[11] A. Reuben, The Higg Index for Sustainable Apparel Environmental Performance Index, 2013, http://epi.yale.edu/indicators/ indicator\%E2\%80\%90case $\%$ E2\%80\%90studies/reports/higg\% E2\%80\%90index.

[12] C. A. Adams and G. R. Frost, "Integrating sustainability reporting into management practices," Accounting Forum, vol. 32, no. 4, pp. 288-302, 2008. 

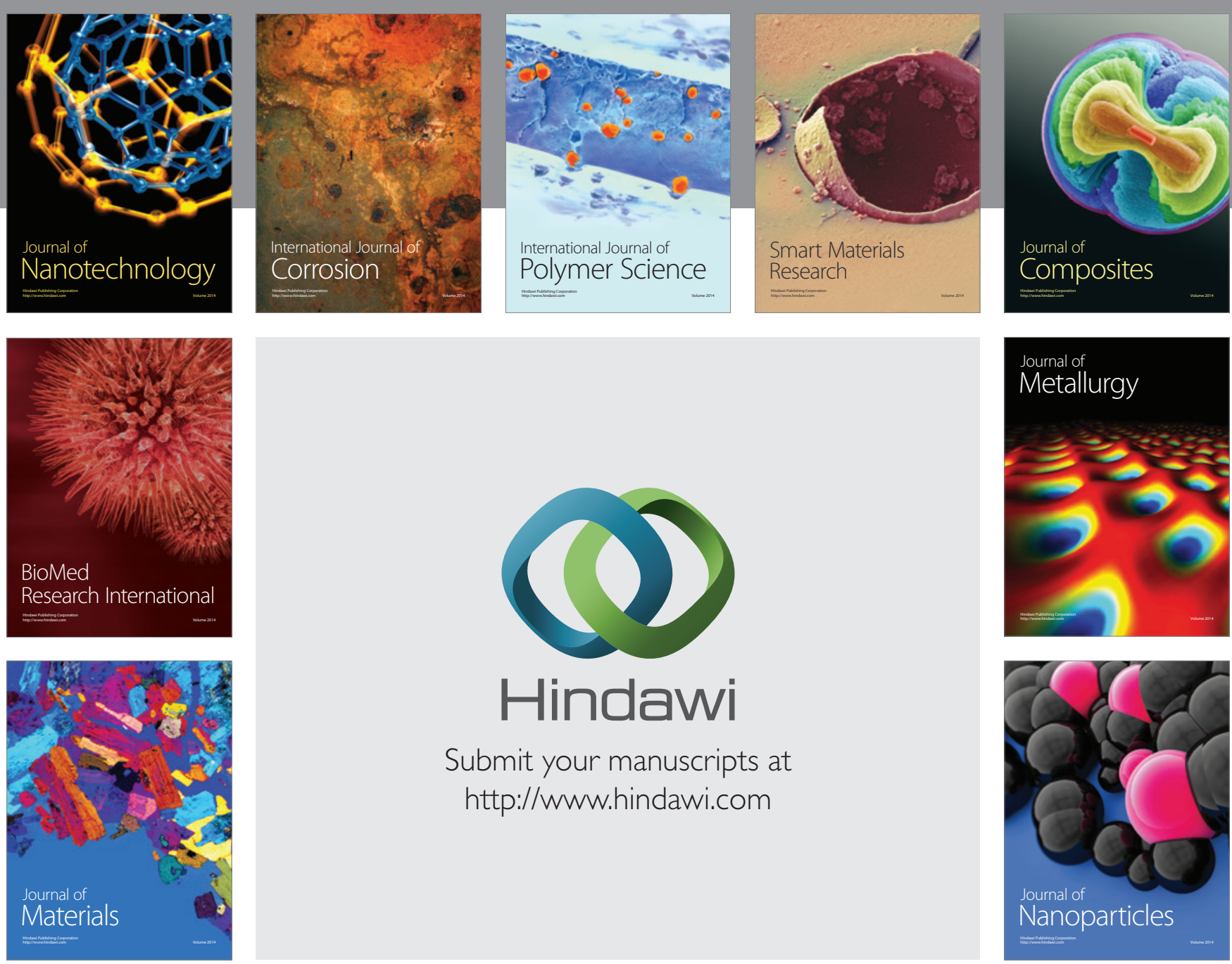

Submit your manuscripts at http://www.hindawi.com
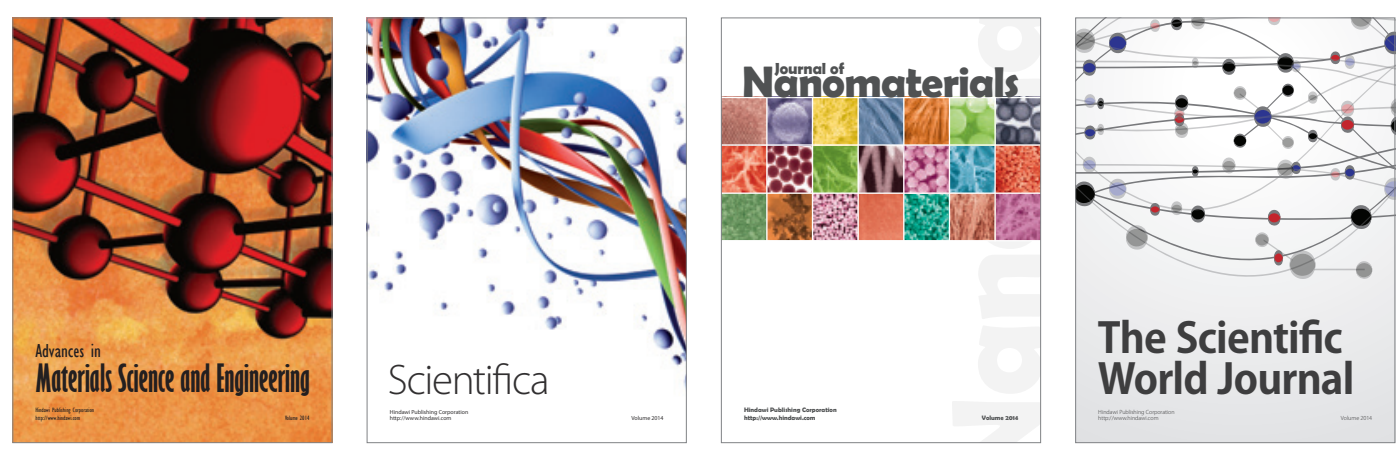

\section{The Scientific World Journal}
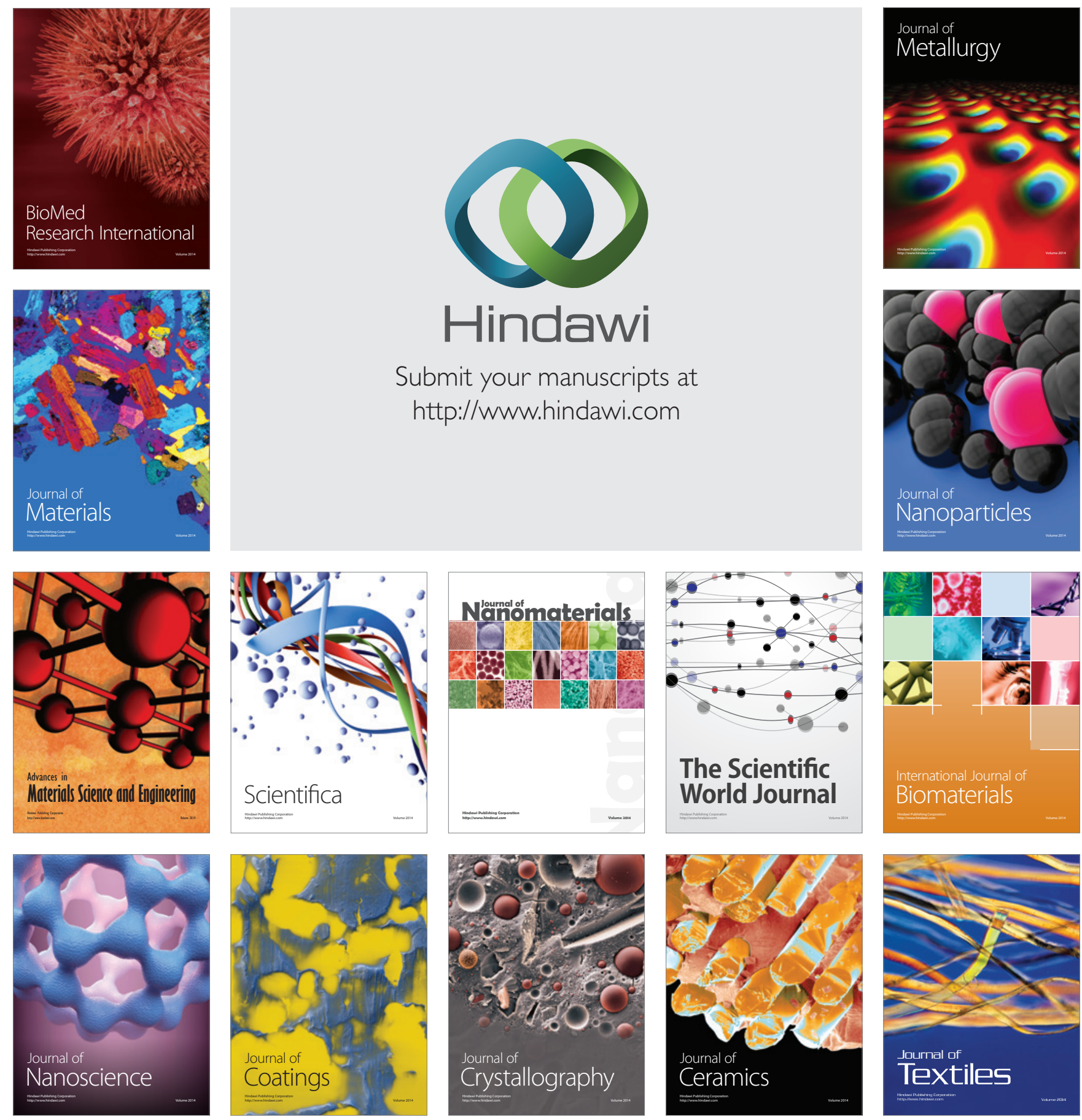